Basrah Journal Of Surgery
Original Article

Bas J Surg, June, 26, 2020

\title{
THE ACCURACY OF ABDOMINAL ULTRASONOGRAPHY IN THE DIAGNOSIS OF ACUTE APPENDICITIS
}

\author{
Ali Hameed Kadhem ${ }^{\circledR}$, Shaymaa Yaqoop Khalid ${ }^{*}$ \& Wisam Hamza Al- \\ Sewadi $^{\#}$ \\ ${ }^{\circledR} \mathrm{MB}, \mathrm{ChB}, \mathrm{CABS}$, Consultant General Surgeon, Alsadr Teaching Hospital. ${ }^{*} \mathrm{MB}, \mathrm{ChB}, \mathrm{CABS}$, Specialist \\ General Surgeon, Alsadr Teaching Hospital, Basrah. ${ }^{*}$ CABS, FACS, FRCS, FICSMRCS, F.MAS, \\ General and laparoscopic Surgeon, Al-Zahraa College of Medicine, University of Basrah, Basrah, IRAQ.
}

\begin{abstract}
Acute appendicitis is the most common causes of abdominal emergencies that necessitate surgical intervention. This study aimed to evaluate the accuracy of abdominal ultrasonography in the diagnosis of acute appendicitis.

This prospective study was performed in Alsadr Teaching Hospital from November 2015 to January 2017 involving 131 patients.

The results showed that $84.7 \%$ of the patients who presented with positive features of acute appendicitis were confirmed by ultrasonographic study, while $15.2 \%$ of the patients showed negative ultrasound examination confirmation.

In conclusion, ultrasound study is effective in the assessment of patients presented with clinical features of acute appendicitis.

Keywords: Surgery, Ultrasound, Abdomen, Acute appendicitis, Diagnosis accuracy
\end{abstract}

\section{Introduction}

$\Delta$ cute appendicitis is one of the most Acommon causes of emergencies which require surgical intervention. Early diagnosis of acute appendicitis is very important for successful outcome ${ }^{1}$. The vermiform appendix is a tubular structure arising from the cecum, it is about $10 \mathrm{~cm}$ long ${ }^{2}$.

Acute appendicitis is an inflammation of the appendix which is either caused by obstructive or non-obstructive factors ${ }^{2}$ and is mainly diagnosed by the clinical picture in which there is anorexia, migratory pain to the right iliac fossa (RIF) and vomiting. On examination, there may be RIF tenderness, rebound tenderness especially at McBurney's point and elevation in body temperature . $^{3}$

Many diagnostic tools are used to assist the diagnosis of acute appendicitis such as the Alvarado score system, plain abdominal film, Barium enema, abdominal ultrasonography and CT scan of the abdomine ${ }^{4}$.

Ultrasound test is a technique that depends on high frequency $(7-7.5 \mathrm{MHZ})^{5}$.
The possible criteria of acute appendicitis in ultrasonography are: non compressible, a peristaltic blind tubular structure, An outer diameter of $6 \mathrm{~mm}$ or more, presence of fecolith, Peri-appendicular fluid or collection, and hyper-vascularization of the appendix on color doppler ${ }^{6}$.

This study aimed to assess the accuracy and effectiveness of abdominal ultrasonography in patients suspected to have acute appendicitis to help in the diagnosis that aid to improve the outcome and decrease the complications.

\section{Patients and methods}

A prospective study was done in Al-Sadr Teaching Hospital from November 2015 to January 2017 on 131 patients.

History and clinical examination were done for all the patients. Patients were sent for WBC counts and GUE. All patients included in the study underwent abdominal ultrasonography using graded compression technique. Features of acute appendicitis which were found by ultrasound were recorded. 
After reaching diagnosis of acute appendicitis, the patients were admitted to the surgical ward, and then were subjected to appendectomy. The specimens of the appendices were send for histopathological examinations. Data about ultrasound, operative and histopathological results were analyzed for sensitivity, specificity, positive predictive value, negative predictive value and accuracy.

\section{Results}

One hundred and thirty one patients were included in this study. They were 69 males accounting for $53 \%$ and 62 females accounting for $47 \%$. The age of the patients ranged from 10 to 70 years with the most frequent age group between 20 to 29 years representing $37.4 \%$ of the cases.

From the patient's symptoms and signs, results were as follows: Anorexia 88.8\%, Right iliac fossa pain $87 \%$, Vomiting $72.5 \%$, right iliac fossa tenderness $96.1 \%$, fever $85.6 \%$, and rebound tenderness $84.3 \%$.

The positive features by ultrasound for acute appendicitis were demonstrated in table I.

Table I: Ultrasonographic findings.

\begin{tabular}{|l|l|l|}
\hline U/S features & No. of patients & Percentage \\
\hline Non compressible & 80 & $61 \%$ \\
\hline Fecolith & 74 & $56.4 \%$ \\
\hline Free fluid & 52 & $39.6 \%$ \\
\hline Distended appendix $\geq 6 \mathrm{~mm}$ & 46 & $35.1 \%$ \\
\hline Mass & 2 & $1.5 \%$ \\
\hline
\end{tabular}

After surgery the specimens were sent for histopathological examination and the results were as shown in table II.

Table II: Histopathological examination result.

\begin{tabular}{|l|l|l|}
\hline Histopathology Results & No. of patient & Percentage \\
\hline Catarrhal inflammation & 74 & $56.4 \%$ \\
\hline Suppuration & 20 & $15.2 \%$ \\
\hline Appendicolith & 18 & $13.7 \%$ \\
\hline Follicular lymphoid hyperplasia & 12 & $9.1 \%$ \\
\hline Chronic inflammation & 2 & $1.5 \%$ \\
\hline Normal & 5 & $3.8 \%$ \\
\hline Total & 131 & 100 \\
\hline
\end{tabular}

The ultrasonographic, operative and histopathological findings regarding sensitivity, specificity, positive predictive values, negative predictive values and accuracy are described in number of patients and percentage in tables III \& IV. 
Table III: True and false positive and negative results.

\begin{tabular}{|l|l|l|}
\hline Result & No. of patient & Percentage \\
\hline True positive & 109 & $83.2 \%$ \\
\hline True negative & 3 & $2.2 \%$ \\
\hline False positive & 2 & $1.5 \%$ \\
\hline False negative & 17 & $12.9 \%$ \\
\hline Total & 131 & 100 \\
\hline
\end{tabular}

Table IV: Sensitivity and specificity predictors of accuracy

\begin{tabular}{|l|l|}
\hline Value & Percentage \\
\hline Sensitivity & $86.5 \%$ \\
\hline Specificity & $60 \%$ \\
\hline Positive Predictive Value & $98.1 \%$ \\
\hline Negative Predictive Value & $15 \%$ \\
\hline Accuracy & $85.4 \%$ \\
\hline
\end{tabular}

\section{Discussion}

Acute appendicitis is one of the most common surgical emergencies that need early management and intervention. In spite of it is common, it should be carefully diagnosed because it has wide range of differential diagnosis such as renal, gynecological, and gastrointestinal pathologies ${ }^{1}$.

In this study, 131 patients were included, number of males was $69(53 \%)$ which is higher than females $62(47 \%)$, and it is a similar frequency as in other studies $^{7,8}$. Acute appendicitis occurs most frequently at the age of 20-29 years in this study, which correlate with other studies ${ }^{7,9}$.

Regarding symptoms and signs of acute appendicitis: anorexia was the most common symptom, right iliac fossa pain is the next symptom in frequency, vomiting was the least common one as found in another study ${ }^{10}$.

There was an increase in WBC counts in 57 patients representing $43.5 \%$ of all patients in this study, while it is within normal range in 74 patients (56.4\%).
Normal WBC counts may occur in elderly, immunocompromised patients, patient with malignancy and others. So WBC counts may not reflect the severity of the disease ${ }^{11}$.

In comparing ultrasound, and histopathological results, it was found that 111 patients $(84.7 \%)$ showed positive findings in ultrasound study, and 109 patients $(83.2 \%)$ were found to be positive by histopathological examination, this represents the true positive results. Two patients $(1.5 \%)$ out of 111 were found positive by ultrasound study and they had negative results by histopathology, this represents the false positive results. Twenty patients $(15.2 \%)$ had no features of acute appendicitis by ultrasound, 17 patients of them (12.9\%) had inflamed appendix on histopathology examination and this represents the false negative results. While three patients $(2.2 \%)$ out of the 20 patients had negative ultrasonographic results and were normal by histopathology, this reflects the true negative results. 
The presence of the appendix in some positions like retrocecal appendix, or when the inflammation confined to the tip of the appendix, the presence of large amount of gas within the bowel loops, or in case of perforated appendix, all these may lead to difficulty in identifying the appendix and thus will give false negative results $^{12}$. There are other abdominal conditions like inflamed Mickle's diverticulum, Crohn's disease, inflamed fallopian tube or tubo-ovarian abscess, these may be falsely identified as inflamed appendix and lead to false positive results ${ }^{12}$. In this study the sensitivity was $86.5 \%$, specificity was $60 \%$, positive predictive value was $98.1 \%$, negative predictive value was $15 \%$, and the accuracy was $85.4 \%$.

In conclusion, the clinical picture in addition to ultrasound findings suggests the diagnosis of acute appendicitis, this combination have significantly high sensitivity and accuracy values in the diagnosis of acute appendicitis especially in cases with atypical presentations.

\section{References}

1. Parsia Javidi Parsijani,NimaPourhhabibi Zarani and Shahram Bolandparvaz. Accuracy of U/S in acute appendicitis.Bulletin of Emergency and Trauma, 2013 Oct;(4):158-163.

2. Jerry L. Old., Reginald W. Dusing, Wendell Yap, and Jared Dirks. Imaging for suspected appendicitis. American family physician, Jan.1, 2005; 71-78.

3. Jonathan RL Wild, Nicole Abdul, Judith E Ritchie, Bo Rud, Sally Freels, RichardL Nelson. U/S for diagnosis of acute appendicitis. Cochrane data base of systemic review, 28 Feb.2013.

4. Subash K., Abhijit De, Mahesh Pathak and Brijesh Sathian. Diagnostic role of U/S in acute appendicitis. American journal of public health research, volume 3, no.5 A, 2015; p23-28.

5. Bimbam BA., Wilson SR. Appendicitis at the millennium RSNA radiology, May 2020; vol 215 , issun 2,377-348.

6. Mohamed Samir, Mohamed Hefzy, Mohamed Gaber, Khaled Moghazy. Added value of graded compression UIS to the Alvarado score of right iliac fossa. African journal of emergency medicine, Sep 2016;vol.6(3):138-143.

7. Rodrigo de Oliveira Peixoto,Tarcizo Afonso Nunes. Indices of diagnostic abdominal U/S in acute appendicitis. Rev.Col.Brazil.Cir. vol -38 Rio de Janeiro, Marchl April2011;105-11.

8. Accuracy of ED sonography in the diagnosis of acute appendicitis. American journal of emergency medicine, vol.18, no.4, July2000;449-452.

9. Clinical presentation of acute appendicitis in adult at the Chrishani Baragwanth academic hospital. International journal of emergency medicine.17,Feb.2014;7:12.

10. Diagnosis of acute appendicitis. International journal of surgery. March2012; vol.19, issue3, 115-119.

11. Clinical value of total WBC and neutrophil counts in patients with suspected appendicitis. World journal of emergency surgery. 20,July2012;7:32.

12. Sonography of acute appendicitis and its mimicin children. Indian journal of radiology.2014;April-June,24(2):163-170. 